\title{
Great bustards Otis tarda in Morocco: status in spring 1999 and evidence of a decline in recent decades
}

\author{
Juan C. Alonso, Simon J. Lane, Robert Dawson and Youssef Idaghdour
}

\begin{abstract}
A spring (1999) census was conducted of great bustards Otis tarda in north-western Morocco, where a poorly known population of this species occurs. Sixty-four birds were seen in four distinct areas. Adult males were seen displaying at three of these areas, indicating that they are probably traditional lek sites. No adult males were observed in the fourth area and its status as a lek site is uncertain. Two further sites were visited but no birds were seen. Two 1st-year males were seen with their mothers, demonstrating
\end{abstract}

\section{Introduction}

The great bustard Otis tarda is a Globally Threatened (Vulnerable) species (Collar et al., 1994), distributed in grassland habitats from eastern Asia, westwards, to the Iberian Peninsula. The species also occurs in northwestern Morocco but, until recently, only a few anecdotal reports were available on the distribution there and only three of these gave any indication of numbers present. In the early 1970s, at least three populations were known: one 'south of Tanger' with 30 birds; one 'north of Larache' with 20 birds; and another further south at a site near Souk-el-Arba-du-Rharb, which was said to hold 10-12 birds (Pineau \& Giraud-Audine, 1977; Collar, 1985). On 28 February 1982, 58 birds, of which 56 were males, were recorded in three flocks 'on the plains around Tanger' (Goriup, 1983 and pers. comm.). Based on these accounts, a total of 100 was considered a reasonable guess for the size of the

\section{J. C. Alonso (corresponding author) Departamento de Ecologia Evolutiva, Museo Nacional de Ciencias Naturales, José Gutierrez Abascal 2, 28006 Madrid, Spain.}

5. J. Lane Departamento de Ecología Evolutiva, Museo Nacional de Ciencias Naturales, José Gutíerrez Abascal 2, 28006, Madrid, Spain and Department of Biological Sciences, University of Newcastle, University Drive, Callaghan, New South Wales 2308, Australia.

R. Dawson The International Foundation for Conservation and Development of Wildlife, PO Box 116, Inezgane, Morocco.

Y. Idaghdour The International Foundation for Conservation and Development of Wildlife, PO Box 116, Inezgane, Morocco.

Received 26 May 1999. Accepted 14 October 1999 successful breeding in 1998. We argue that the small number of birds, a population sex ratio of $1: 3.3$ in favour of females, evidence for a range contraction, and probable isolation from other great bustard populations mean that this population is now extremely endangered and will decline to extinction unless conservation measures are implemented immediately.

Keywords Conservation, extinction risk, great bustard, Morocco, Otis tarda, population trends, status.

Moroccan great bustard population in the mid-1980s (Collar, 1985). In the absence of further information, this figure subsequently pervaded the literature unquestioned (e.g. Urban et al., 1986; Johnsgard, 1991; Collar et al., 1994; Alonso et al., 1995; del Hoyo et al., 1996).

In 1998, at the behest of The International Foundation for Conservation and Development of Wildlife (Inezgane, Morocco), three surveys (spring, summer and winter) were conducted in north-western Morocco covering areas where great bustards had been reported previously and also arable steppes where the species might be expected to occur (Hellmich, 1999). The surveys estimated 66 birds in March, and 28 and 90 were counted in July and December, respectively. The December count represents the current minimum estimate of the number of great bustards in Morocco, although interviews with local people suggested that the total might be as high as 133 (Hellmich, 1999). Hellmich's work was the first serious attempt to survey the species in Morocco and greatly improves knowledge of the species's only known African population. However, in the case of the spring data, the sex ratio and approximate age structure of flocks at proposed breeding sites (leks) are missing because some information was based on interviews with local people rather than sightings of the birds themselves.

Data on the sex ratio in spring are particularly important because they indicate the conservation status of flocks attending lek sites and, therefore, of the breeding population. In the case of the great bustard, there is a natural sex bias towards females, as is typical for polygynous species exhibiting sexual size dimorphism. Adult 
males typically weigh $11-12 \mathrm{~kg}$ (exceptionally more) but females only weigh about $4-5 \mathrm{~kg}$, and large, protected populations usually have a sex ratio of between $1: 1.5$ and $1: 1.8$ (e.g. Villafáfila, north-west Spain, 2100 birds; Sierra de Fuentes, western Spain, 800 birds; see Alonso \& Alonso 1990; Alonso et al., 1995). Data for smaller, more threatened populations show a higher sex bias, probably as a result of the increased vulnerability of males to some mortality factors (e.g. collisions with powerlines, which is the main mortality cause in this species (Alonso et al., 1994, 1995, unpublished data), and past selective hunting or recent occasional poaching of males (see Alonso \& Alonso, 1996)). For example, in Madrid province, Spain, where the population is fragmented into several small units, each suffering a variety of man-induced pressures, the average adult sex ratio in 1998 was $1: 2.5$ with some areas having biases in excess of $1: 3$ (Alonso et al., unpublished data), whereas in some extremely endangered leks in southern Spain the sex ratio in 1999 reached extreme values of $1: 3.8$ and even $1: 14$ (Lane \& Alonso, unpublished manuscript).

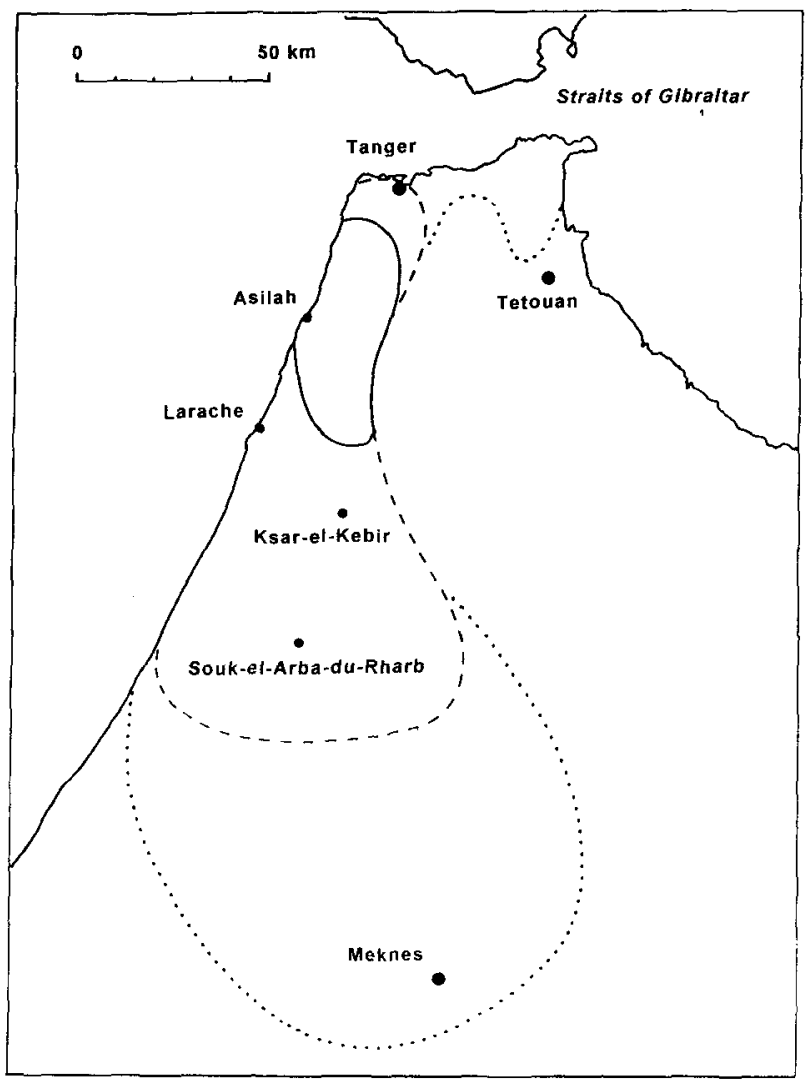

Fig. 1 Past and present distribution of great bustards in Morocco. The solid line indicates present (1999) known limits, while dashed and dotted lines are the estimated limits for the early 1980 s and the first half of the 20th century, respectively.
We stress, however, that inferences on the structure of flocks at breeding sites cannot be made from data collected at other times of the year because great bustards make complex seasonal movements between breeding and non-breeding areas, which at present are fully understood only in parts of Spain where radiotracking studies have been undertaken (e.g. Villafáfila and Madrid; Alonso et al., 1998; Alonso et al., 2000; Morales et al., 2000; J. C. Alonso, unpublished data) and are totally unknown in Morocco. We, therefore, conducted a spring (1999) census of great bustards in Morocco in which our primary aim was to provide data on the current status and structure of the flocks attending possible lek sites. A secondary objective was to search additional sites that Hellmich (1999) suspected might hold great bustards but where none was recorded in his surveys. Finally, we examined the literature for any evidence of a decline in the last few decades. Based on the accumulated evidence, we discuss the urgent need for research, monitoring and conservation intervention for this population.

\section{Methods}

The fieldwork was carried out from 11 to 13 March 1999 in north-west Morocco, centring on the town of Asilah (Fig. 1). We worked initially in the four areas where Hellmich (1999) had located possible leks the previous spring (comprising a total of c. $400 \mathrm{sq} \mathrm{km}$ of possible bustard habitat within the solid line in Fig. 1). On the morning of 13 March, we travelled to an area (c. $100 \mathrm{sq} \mathrm{km}$ ) c. $10 \mathrm{~km}$ east of El-Ksar-el-Kebir, which was identified by Hellmich (1999) as a potential great bustard lek site but where he had been unable to locate any flocks. Other potential areas further south (c. $400 \mathrm{sq} \mathrm{km}$ within the dashed line in Fig. 1, north and south of Souk-el-Arba-du-Rharb) were not visited because there are no recent reports or sightings of birds, and several unsuccessful searches were conducted in these places during 1998 (compiled in Hellmich, 1999). During our surveys, we always interviewed numerous local people to confirm the recent or past presence of great bustards.

Surveys were conducted in a four-wheel-drive vehicle by observers equipped with binoculars and $\times 20-60$ telescopes. When great bustards were seen, the number, sex and age of males $(<1$ year, probably $2-3$ years, $>3$ years) were recorded. Females, including those less than 1 year old, cannot be aged at this time of the year. We considered the location of male flocks in March to be indicative of the lek site at which they would display and copulate in April. When found, female flocks were assigned to the lek closest to them. These assumptions are based on an extensive data set, 
Table 1 Status and structure of great bustard Otis tarda populations at known, or suspected, lek sites in north-western Morocco, 11-13 March 1999

\begin{tabular}{|c|c|c|c|c|c|c|}
\hline Location & Adult males & $\begin{array}{l}\text { 2nd-3rd-year } \\
\text { males }\end{array}$ & 1st-year males & Females & Total & Sex ratio male : female \\
\hline El Louche & 5 & 1 & 0 & 8 & 14 & $1: 1.3$ \\
\hline Oued-el-Hachef & 0 & 0 & 0 & 0 & 0 & - \\
\hline South of Asilah & 1 & 1 & 0 & 22 & 24 & $1: 11$ \\
\hline El Araoua & 4 & 1 & 1 & 10 & 16 & $1: 1.7$ \\
\hline Charkia/El Ksiba & 0 & 0 & 1 & 9 & 10 & $?$ \\
\hline East of El Ksar-el-Kabir & 0 & 0 & 0 & 0 & 0 & - \\
\hline Total & 10 & 3 & 2 & 49 & 64 & $1: 3.3$ \\
\hline
\end{tabular}

spanning 15 years, at sites in central and north-west Spain (Morales, 1999; J. C. Alonso et al., unpublished data). As a result of the strong breeding site fidelity of both males and females (Alonso et al., 2000; Morales et al., 2000), we think that our survey could be considered as a reasonably accurate estimate of the current breeding status of the species in Morocco.

Locations of observation points were obtained using a Geographic Positioning System and were within $200 \mathrm{~m}$ of the flocks. In the interests of security for this population these co-ordinates are not presented here, but are available to bona fide researchers from J.C.A. or R.D.

\section{Results}

We observed a total of 64 great bustards distributed between four distinct areas (Table 1). In three of these, male flocks were recorded, thus indicating their probable status as lek sites. The largest number of birds was seen at south Asilah, which we visited on two occasions. On 11 March, we saw one adult male c. $100 \mathrm{~m}$ from a flock of 22 females. Two days later, we saw the same birds in the same location, and also a 2nd-year male flying through the area, which then landed a little to the south. A shepherd told us that 2-3 males had displayed in this area the previous year, although Hellmich (1999) recorded only one in late March 1998.

We saw 14 birds at El Louche, of which eight were female. However, the vegetation was very tall and we may have missed a female flock, even though we made two visits. At El Araoua, we recorded 16 birds, 10 of which were female, and we were more confident that we had seen all birds present. A 1st-year male in the company of its mother indicated a successful breeding in 1998. At Charkia/El Ksiba, we found one female flock in which the second of the two male chicks seen was noted. Although these birds were c. $10 \mathrm{~km}$ from the males at El Araoua, the absence of another male flock in the area suggests that they might be part of the same lek.
The sex ratio for birds within sites varied from $1: 1.3$ at El Louche to $1: 11$ at south Asilah. If we did miss a female flock at El Louche, then the sex ratio for this site is conservative and the overall sex ratio of $1: 3.3$ between the four sites is similarly compromised. If the females of Charkia/El Ksiba are part of the El Araoua lek, then the sex ratio for this area increases from $1: 1.7$ to $1: 2.7$.

There were two areas in which no great bustards were seen (Table 1). At the site east of El Ksar-el-Kabir, a local man reported seeing four birds the previous month, while most others said that they had seen none in the last 2 years. At Oued-el-Hachef, Hellmich (1999) saw 12 birds in December 1998 but, like us, none in the spring.

\section{Discussion}

\section{Status of leks}

All males aged greater than 1 year were seen in El Louche, El Araoua and the Asilah site. The fact that we observed males displaying at the first two of these, together with the shepherd's information at Asilah, indicates that these areas are traditional great bustard lek sites. Moreover, Hellmich (1999) had also observed birds displaying at these sites the previous year. At the Charkia/El Ksiba site, no adult males were seen and, consequently, its status as a lek site is uncertain. The female flock here was within $10 \mathrm{~km}$ of the males at El Araoua and could belong to this lek. Alternatively, if Charkia/El Ksiba is a traditional lek, then two explanations might account for the absence of males. First, we might have missed them, but we doubt that this is the case because we spent $5 \mathrm{~h}$ surveying the area. Second, all of the males might have died, thus rendering the lek effectively extinct. This does seem possible in view of the small number of males at the other leks. Consider the two at south Asilah. If they should die before being joined by others, then an ornithologist visiting the area for the first time might encounter 
a flock of 22 females and then search in vain for the male flock.

Our total count of birds was 26 fewer than the 90 that Hellmich (1999) recorded the previous December. The whereabouts of these missing birds is open to considerable speculation. We think we may have missed some, probably females, at El Louche, although it is possible that another small lek exists. The site east of El Ksar-el-Kabir can probably be eliminated as a lek site, although it might have held birds previously. Ouedel-Hachef may be a wintering area rather than a lek. There is also an outside chance that some birds might winter in Morocco and move to Spain to breed. This has never been demonstrated and we think that it is improbable, although the distance to the nearest Spanish great bustard site is less than $100 \mathrm{~km}$, which is within the range of seasonal movements demonstrated through radiotracking in central Spain (authors' unpublished data).

\section{Evidence for a decline in the Moroccan great bustard population}

Information on the population trend of great bustard in Morocco is scarce, but three lines of evidence indicate that numbers have declined and that the population is critically endangered. First, the overall sex ratio of $1: 3.3$ suggests that mortality rates for males are abnormally high, even when compared with threatened great bustard populations elsewhere, such as those near Madrid or in southern Spain (Alonso et al., unpublished manuscript). In fact, one of the most startling results of this study is how few males are present in the population. We suspect that this might be the result of selective killing of adult males for trophies. In his interviews with local people, Hellmich (1999) established that illegal poaching of this species is quite common and would explain the massive sex bias observed at south Asilah. For this reason, we have been imprecise with flock locations in this report.

The second, and related, line of evidence for a decline is based on comparison with Goriup's (1983 and pers. comm.) account of 42 mature plus 14 immature males seen in February 1982. The birds were seen in four flocks at only two areas, which correspond to El Louche and El Araoua of our Table 1, where we saw a total of nine males plus two immature birds. If we conservatively compare only adult numbers, then this suggests that this component of the population has decreased by 79 per cent over the intervening period in the current range. If we include immature birds, then the decline has been even greater.

Finally, there is also evidence of a possible range contraction during the 20 th century. Range contraction can usefully indicate that a population is in trouble, even when the size of the population in the past is not known. In Fig. 1, the dotted line is our projection of the range during the first half of the 20th century based on two early references in Collar (1985). The southern limit is close to the town of Meknes, near which great bustards were said to breed, and the north-eastern point is close to Tetouan, where the species was also seen. We suppose that the birds occurred in the plains to the west of a mountainous region, which therefore delimits the eastern boundary. In the 1970 s and early 1980 s, the most northern and southern populations of great bustards were reported near Tanger and Souk-el-Arba-du-Rharb, respectively (Collar, 1985). The possible range limit is indicated by the dashed line within which searches have been conducted recently but no birds found (Hellmich, 1999; this study). However, at some sites local people reported having seen great bustards, which, if true, would considerably extend the currently (1999) known range (Fig. 1).

The evidence for a decline and Hellmich's (1999) estimates of 90-133 individuals still surviving in December 1998 make it clear that Collar's (1985) widely quoted population estimate of 100 individuals in the mid-1980s was too conservative. It is difficult to say how many birds were present then; however, if a sex ratio of $1: 2.5$ is assumed in 1982, then, in addition to the 42 adult males, 105 adult females may also have been present but not observed and, therefore, 147 adults overall. Now add the 14 immature males also seen by Goriup (1983) and, for the sake of argument, an equal number of immature females and the estimate increases to 175 . This should be regarded as a minimum estimate because Goriup's (1983) party probably did not see all adult males in Morocco on a single day's observation, and the sex ratio might already have been more heavily biased in favour of females.

\section{Implications for conservation}

There can be little doubt that great bustards in Morocco are critically endangered. The extreme sex ratio of $1: 3.3$ (which is probably even more biased if one allows for the females that may have been missed), and the very small number of adult males in the population, coupled with reports of trophy hunting, give special cause for concern. Furthermore, the Moroccan population is probably too isolated to receive dispersing males from the Iberian Peninsula. Other factors limiting the population are probably many and varied; however, they are likely to include reduced nesting success as a result of disturbance and trampling of nests by livestock, both of which occur at high density, and collision of flying birds with cables. If this population is to survive, 
immediate conservation intervention is required to address these issues, preferably backed by a research programme and regular monitoring to diagnose accurately the factors driving the decline.

\section{Note}

Since this article went to press, we have received a letter from Dr Zine Laabidin Arhzaf, President of the Association for Environmental Education and Bird Protection in Morocco (SEEPOM). He reported that six adult great bustards (three males, three females) were observed on 27 March 1999, in an area about $80 \mathrm{~km}$ north of Meknes, south-east of Souk-el-Arba-du-Rharb. We did not survey this area in 1999, although several unsuccessful searches were conducted there during 1998. Local people informed Dr Arhzaf of the presence of some 20 great bustards in that area; at least one young bird was shot in 1999. This observation increases the total count of Moroccan great bustards to 70 birds seen at five distinct areas, with at least four lek sites where adult males were present in March 1999. Adding the 20 birds reported by local people, the total census reaches $90-100$ birds, a number close to that reported by J. Hellmich in December 1998 (Hellmich, 1999). The area between Meknes and Souk-el-Arba-du-Rharb probably represents the southernmost breeding site for Moroccan great bustards, coinciding with the southernmost location reported by N. Collar in the early 1980 s (Collar, 1985). Furthermore, it extends the species' current distribution to the dashed line shown on Fig. 1, as we suspected (see third paragraph of second section of Discussion).

\section{Acknowledgements}

S.J.L. and J.C.A. conceived the idea of censusing great bustards in Morocco prior to their knowledge of $\mathrm{J}$. Hellmich's work in 1998. By proceeding with a census in 1999, there was then the risk of 'stealing his thunder'; however, in the true spirit of collaboration, J. Hellmich provided us with a draft of his report including information on the locations of all flocks he had recorded. We acknowledge that the success of our census was largely the result of this generosity for which we thank him warmly. The survey was co-financed by the British Ecological Society (SEPG No. 1577 to S.J.L.) and The International Foundation for Conservation and Development of Wildlife (IFCDW), Inezgane, Morocco, who generously provided a car and driver. Particular thanks are given to Dr Sami Jamil Jadallah for his encouragement and support, and to His Royal Highness Prince Sultan bin Abdul Aziz al Saud of the Kingdom of Saudi Arabia, patron and sponsor of IFCDW. S.J.L. was supported by a Marie Curie Research Training Grant awarded under the Training and Mobility of Researchers Programme by the European Commission Directorate General XII.

\section{References}

Alonso, J.A., Alonso, J.C., Martín, E. \& Morales, M.B. (1995) The Great Bustard in the Reserve of Las Lagunas de Villafáfila. Inst. Estudios Zamoranos-CSIC, Zamora [in Spanish and English].

Alonso, J.C. \& Alonso, J.A. (eds) (1990) Parametros Demograficos, Seleccion de Habitat y Distribucion de la Avutarda (Otis tarda) en Tres Regiones Españolas. Colección Técnica, ICONA, Madrid [in Spanish with English summary].

Alonso, J.C. \& Alonso, J.A. (1996) The great bustard Otis tarda in Spain: present status, recent trends and an evaluation of earlier censuses. Biological Conservation, 77, 79-86.

Alonso, J.C., Alonso, J.A. \& Muñoz-Pulido, R. (1994) Mitigation of bird collisions with transmission lines through groundwire marking. Biological Conservation, 67, 129-134.

Alonso, J.C., Martín, E., Alonso, J.A. \& Morales, M.B. (1998) Proximate and ultimate causes of natal dispersal in the great bustard Otis tarda. Behavioral Ecology, 9, 243-252.

Alonso, J.C., Morales, M.B. \& Alonso, J.A. (2000) Partial migration, and lek fidelity and nesting area fidelity in female great bustards Otis tarda. The Condor, 102, 127-136.

Collar, N.J. (1985) The world status of the great bustard. Bustard Studies, 2, 1-20.

Collar, N.J., Crosby, M.J. \& Stattersfield, A.J. (1994) Birds to Watch 2. Birdlife International, Cambridge.

Goriup, P. (ed.) (1983) The houbara bustard in Morocco. Report of the Al-Areen/ICBP March 1982 preliminary survey. ICBP, Cambridge.

Hellmich, J. (1999) The great bustard Otis tarda L. in Morocco 1998. Unpublished report to The International Foundation for Conservation and Development of Wildlife, Inezgane, Morocco.

del Hoyo, J., Elliot, A. \& Sargatal, J. (eds) (1996) Handbook of the Birds of the World, vol. 3. Hoatzin to Auks. Lynx Edicions, Barcelona.

Johnsgard, P.A. (1991) Bustards, Hemipodes and Sandgrouse: Birds of Dry Places. Oxford University Press, Oxford.

Morales, M.B. (1999) Ecología reproductiva y movimientos estacionales en la avutarda (Otis tarda). PhD thesis, Complutense University, Madrid.

Morales, M.B., Alonso, J.C., Alonso, J.A. \& Martín, E. (2000) Migration patterns in male great bustards (Otis tarda). $A u k$, in press.

Pineau, J. \& Giraud-Audine, M. (1977) Notes sur les oiseaux nicheurs de l'extreme nord-ouest du Maroc: reproduction et mouvements. Alauda, 45, 75-103 [in French].

Urban, E.K., Fry, C.H. \& Keith, S. (eds) (1986) The Birds of Africa, vol. 2. Academic Press, London. 


\section{Biographical sketches}

Dr Juan C. Alonso is a researcher at the Museo Nacional de Ciencias Naturales, Madrid, where he has worked on behavioural ecology and conservation biology of endangered bird species, particularly common cranes, great bustards and various raptor species. He is currently co-ordinating a research project on the dispersal, genetics and metapopulation structure of the great bustard in Spain.

Dr Simon Lane has worked in Japan and the UK with wildlife management problems in agricultural environments. In 1997, he was awarded an EU RTM grant to investigate the space and resource requirements of the great bustard at the Museo Nacional de Ciencias Naturales, Madrid. He has recently moved to the University of Newcastle, Australia, where he is now dedicating his time to amphibian declines while maintaining a strong interest in the biology of the bustard.

Dr Bob Dawson is currently Scientific Co-ordinator at IFCDW with a primary interest in conservation genetics. Most recently, this has concerned the application of DNA markers to reintroduction projects and for non-invasive population monitoring, especially for houbara bustard and bald ibis. Youssef Idaghdour graduated from Université Ibnou Zohr, Agadir, specializing in molecular biology. He gained valuable field experience with bald ibis and great bustard in Morocco, and at IFCDW is currently focusing on conservation genetic aspects of the houbara bustard. 